\title{
Evaluation of CdS Interfacial Layers in ZnO Nanowire/Poly(3-Hexylthiophene) Solar Cells
}

\author{
John W. Murphy, Israel Mejia, Bruce E. Gnade, and Manuel A. Quevedo-Lopez
}

The University of Texas at Dallas, 800 West Campbell Road, Richardson, TX 75080-3021, USA

Correspondence should be addressed to John W. Murphy, johnwmurphy@utdallas.edu

Received 26 February 2012; Accepted 17 April 2012

Academic Editor: Sevan P. Davtyan

Copyright ( $) 2012$ John W. Murphy et al. This is an open access article distributed under the Creative Commons Attribution License, which permits unrestricted use, distribution, and reproduction in any medium, provided the original work is properly cited.

We prepare ZnO:poly(3-hexylthiophene) (P3HT) thin-film solar cells and ZnO nanowire:P3HT nanostructured solar cells and evaluate the effect of adding an interfacial layer between the $\mathrm{ZnO}$ and $\mathrm{P} 3 \mathrm{HT}$ as a function of the nanowire height. We evaluate several different interlayers of CdS deposited, using two different chemical bath deposition (CBD) recipes. The height of the nanowire array is varied from a bilayer device with no nanowires up to arrays with a height of $2 \mu \mathrm{m}$. We find that achieving a conformal coating of the $\mathrm{ZnO}$ with the interfacial layer is critical to improve device performance and that CBD can be used to grow conformal films on nonuniform surfaces.

\section{Introduction}

Zinc oxide is an exciting semiconductor material for a variety of reasons: it is environmentally friendly, biocompatible transparent, and capable of being deposited by solutionbased processes $[1,2]$. Another interesting property of this material is that it can be grown as vertical arrays of nanowires from a seeded substrate at low temperature in aqueous solutions, as first described by Greene et al. in 2003 [3]. The nanowires, which can be grown to lengths of tens of microns, are single crystals, with excellent electrical properties, despite being grown close to room temperature [4]. These aligned one-dimensional nanowire arrays offer a promising substrate to fabricate solar cells on by providing a direct pathway for charge transport and providing a large effective junction area $[5,6]$.

Solution processed $\mathrm{ZnO}$ nanowire heterojunctions and devices have been reported for a variety of materials already. There were initial reports from Law et al. and a more recent one from Ko et al. on dye-sensitized solar cells [4, 7]. All-oxide $\mathrm{p}-\mathrm{n}$ junctions have been formed between $\mathrm{ZnO}$ nanowires and sputtered $\mathrm{NiO}$, and thin film solar cells made from $\mathrm{ZnO}$ nanowires: $\mathrm{CuO}$ nanoparticles have been reported $[8,9]$. There are also reports of junctions formed with the
$\mathrm{ZnO}$ nanowires with intrinsic a-Si, as well as $\mathrm{p}-\mathrm{i}-\mathrm{n}$ coaxial diodes deposited on top of a conductive Al-doped $\mathrm{ZnO}$ nanowire array $[10,11]$.

$\mathrm{ZnO}$ :P3HT excitonic solar cells in which $\mathrm{ZnO}$ is the acceptor material are an attractive technology because the use of PCBM can be avoided, which is considerably more expensive than $\mathrm{ZnO}$ or its precursors. Although solar cell efficiencies utilizing $\mathrm{ZnO}$ as an acceptor are relatively low compared to P3HT:PCBM-based devices, the use of these $\mathrm{ZnO}$ nanostructured arrays has been demonstrated using P3HT $[12,13]$. It has also shown that the performance of these $\mathrm{ZnO}$ :P3HT hybrid solar cells can be improved with the addition of a thin interlayer between the $\mathrm{ZnO}$ and $\mathrm{P} 3 \mathrm{HT}$; this layer may be an organic material $[14], \mathrm{TiO}_{2}[15,16]$, or $\mathrm{CdS}$ [17].

In this work, we evaluate the performance of $\mathrm{ZnO}$ nanowire:P3HT solar cells with different CdS interlayers. We first examine the effect of thickness using a single chemical bath deposition (CBD) recipe and then compare the performance of two different CBD recipes for a similar thickness CdS layer. All of the devices, with no interlayer and with the three different interlayers are studied as a function of nanowire height. 
(3) $\mathrm{ZnO} \mathrm{NW}$ growth
(1) Pattern ITO

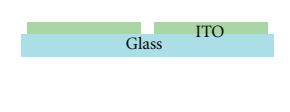

(4) CdS interlayer deposition

Cds

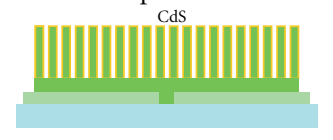

(2) $\mathrm{ZnO}$ sol-gel

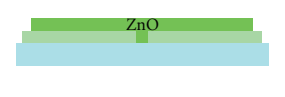

(5) $\mathrm{P} 3 \mathrm{HT}$

spincoating

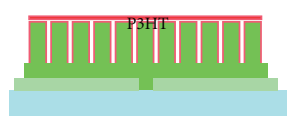

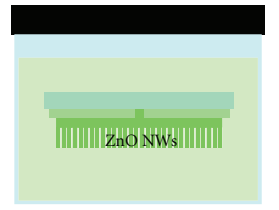

(6) Top metal

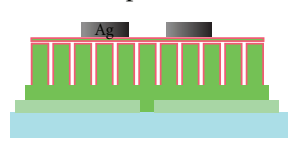

Figure 1: Cartoon flow diagram for device processing.

\section{Experimental Methods}

All devices were fabricated on glass coated with indium tin oxide (ITO) purchased from Luminescence Technology Corporation with a sheet resistance of $15 \Omega / \square$; cross-sectional samples for electron microscopy were prepared on silicon wafers coated with $\mathrm{Cr}$, for ease of imaging. The seed layer was prepared by spin-coating a $\mathrm{Zn}$ sol-gel three times, with a ten-minute hot-plate bake in air at $300^{\circ} \mathrm{C}$ after each spincoat. Afterwards, the samples were annealed in air at $350^{\circ} \mathrm{C}$ for 30 minutes. This sol-gel seed layer was kept constant for all samples; it was prepared to be relatively thick $(\sim 100 \mathrm{~nm})$ to avoid any shorting between P3HT and the ITO electrode.

The $\mathrm{ZnO}$ nanowires were grown from an aqueous $25 \mathrm{mM} \mathrm{Zn}$-nitrate solution with the addition of $25 \mathrm{mM}$ hexamethylenetetramine (HMTA) and $5 \mathrm{mM}$ polyethylenimine (PEI), as described by Law et al. $[4,18]$. The substrates were suspended face down in the solution in sealed vessels and allowed to react for between 2.5 and 10 hours, producing nanowire arrays with a height of $500-2000 \mathrm{~nm}$; in total, we evaluated four thicknesses of nanowires: $0 \mathrm{~nm}$ or bilayer devices, 500, 1000, and $2000 \mathrm{~nm}$. When the reaction was terminated, the samples were cleaned by rinsing in DI water, briefly sonicating facedown in DI water, and then rinsing again before drying with nitrogen. Before depositing the interlayer (or the $\mathrm{P} 3 \mathrm{HT}$ for the $\mathrm{ZnO}$ only samples), the $\mathrm{ZnO}$ films were annealed in air at $350^{\circ} \mathrm{C}$ for 30 minutes in order to remove any residual PEI on the nanowires.

Three different CdS interlayers were evaluated using two different chemical bath deposition (CBD) recipes. The first CBD recipe was first reported by Sotelo Lerma et al. in 1998 and was more recently used by Salas Villasenor et al. to produce thin-film, high-mobility CdS transistors [19, 20]. Briefly, this reaction is carried out by submersing the substrates in an aqeous solution of $\mathrm{CdCl}_{2}$, sodium citrate, $\mathrm{KOH}$, and thiourea $70^{\circ} \mathrm{C}$ for 25 mins. Two different film thicknesses were produced using this recipe, by carrying out the CBD process either one or three times; these devices will hereafter be referred to as 1-dip and 3-dip CdS films.

The second CBD recipe was developed by Spoerke et al. and is carried out simply by immersing the samples in an aqueous solution of $\mathrm{Cd}\left(\mathrm{NO}_{3}\right)_{2}$ and thioacetamide for 25 minutes [21]. These samples will hereafter be referred to as
EZ CdS, due to the simplicity of the procedure. In total, four sets of devices were fabricated: $\mathrm{ZnO}$ only, 1-dip CdS, 3-dip CdS, and EZ CdS.

The P3HT, purchased from Sigma Aldrich $\left(M_{W}=\right.$ 25000 ), was deposited by spin coating a $30 \mathrm{mg} / \mathrm{mL}$ chloroform solution onto the $\mathrm{ZnO}$ layer at $2000 \mathrm{RPM}$ in a nitrogen glove box; they were then annealed at $150^{\circ} \mathrm{C}$ in the same glove box before being transferred (through air) to another glove box for metallization. The samples were completed by evaporation of $100 \mathrm{~nm}$ of $\mathrm{Ag}$ through a shadowmask to define devices of $9 \mathrm{~mm}^{2}$. Figure 1 shows an overview of the processing steps.

Characterization of the films was performed using a Rigaku Ultima III X-ray diffractometer, a Zeiss Supra SEM, and an Agilent 8453 UV-Vis spectrophotometer; IV measurements were carried out with a Keithley 2400 sourcemeasure unit in conjunction with an AM1.5-simulated light source, and the capacitance measurements were done in the dark using an Agilent 4284 LCR meter. The solar cell efficiencies were calculated by sweeping the voltage from -1 to $1 \mathrm{~V}$ under illumination and then dividing the maximum power density point by the spectral power density of the lamp source $\left(100 \mathrm{~mW} / \mathrm{cm}^{2}\right)$. All solar cell data represent the average of at least three separate devices.

\section{Results and Discussion}

Figure 2 shows the morphology of the $\mathrm{ZnO}$ nanowires grown for $10 \mathrm{hrs}$ (thickness $2000 \mathrm{~nm}$ ) with no interlayer, and with the 1-dip and 3-dip CdS interlayer coatings. It appears that the 1-dip coating may not completely coat the $\mathrm{ZnO}$ nanowires, as evidenced by the particulate-like coating apparent on some of the nanowires. The 3-dip images show a thicker and more continuous coating of the nanowires, particularly towards the top of the array. We estimate from the SEM micrographs that the 1-dip coating is $5-10 \mathrm{~nm}$ thickness and the 3 -dip coating is $20-30 \mathrm{~nm}$.

Figure 3 shows the XRD spectra for the $\mathrm{ZnO}$ only, 1dip, and 3-dip films before deposition of the P3HT layer. The primary peak for the $\mathrm{ZnO}$ nanowires, representing the (002) plane of wurtzite $\mathrm{ZnO}$, is at $2 \theta$ equals $34.43^{\circ}$. The $0 \mathrm{~nm}$ spectra, for no nanowire growth, show that the 1- and 3dip CdS interlayers cause only a small degree of attenuation 


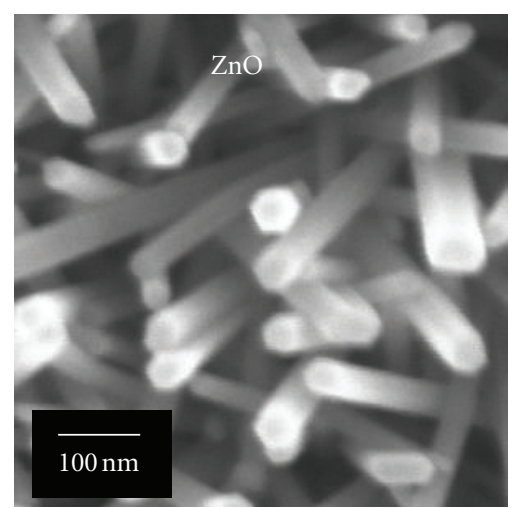

(a)

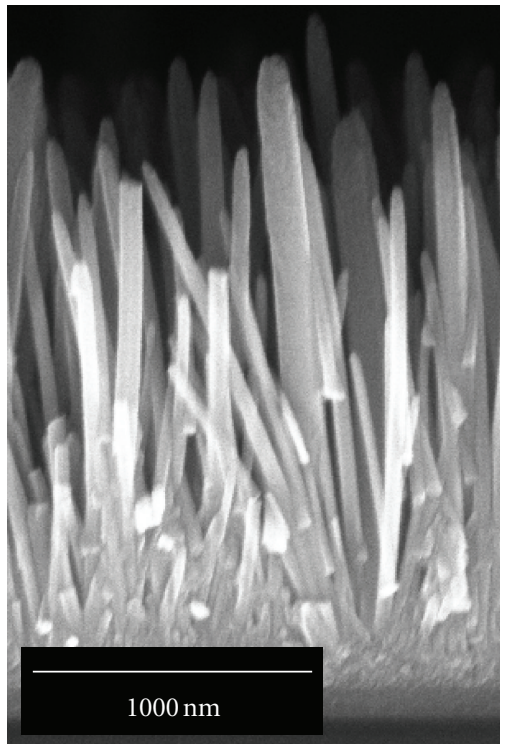

(d)

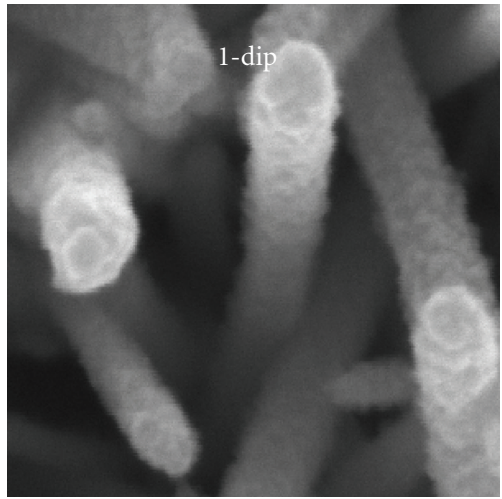

(b)

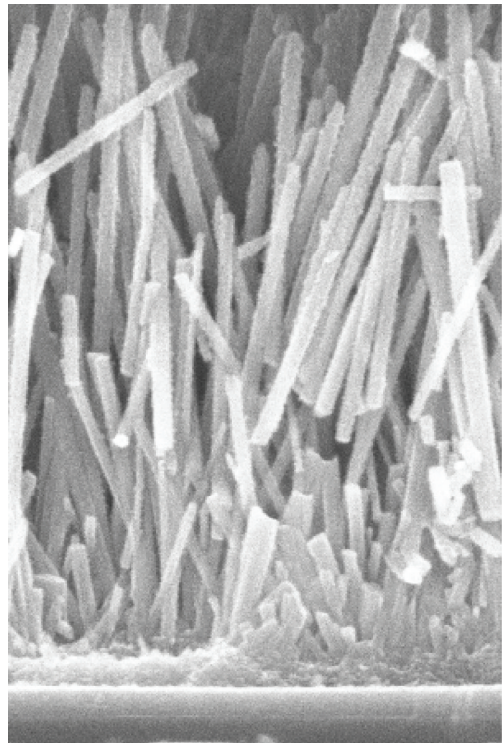

(e)

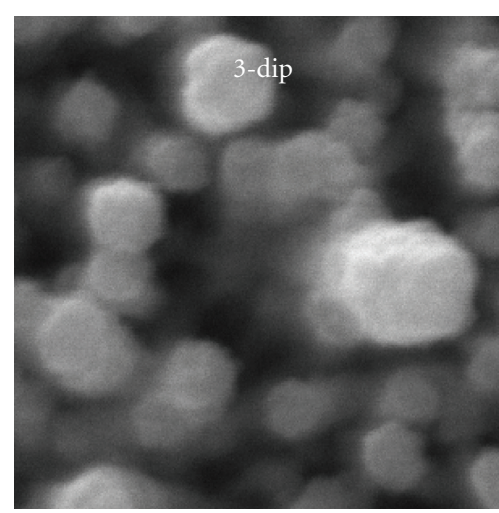

(c)

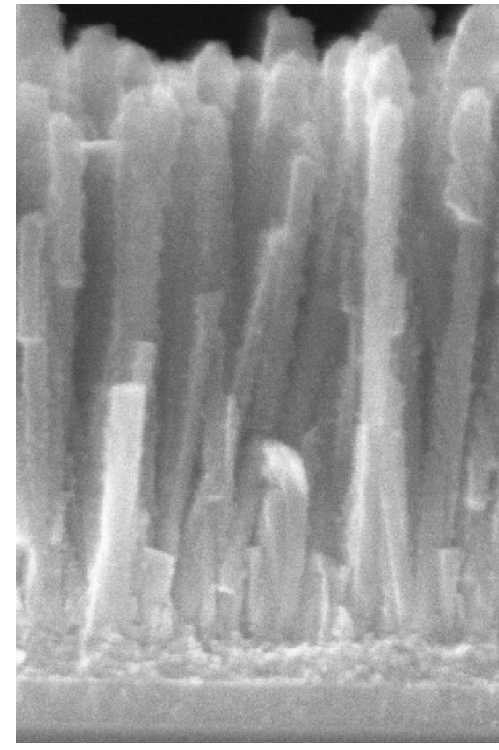

(f)

FIGURE 2: Lateral (top) and cross-section (bottom) SEM images of ZnO nanowires grown for 10 hours, approximately $2000 \mathrm{~nm}$ tall, with no interlayer (left), 1-dip CdS (middle), and 3-dip CdS (right) interlayers. The top $100 \mathrm{~nm}$ scale bar is for the lateral images, and the bottom $1000 \mathrm{~nm}$ scale bar is for the cross-section images.

to the underlying $\mathrm{ZnO}$ peaks. Also, by comparing the 1and 3-dip spectra for the 0 and $500 \mathrm{~nm}$ nanowire films, it appears that the 3-dip CdS produces larger crystallites of (002) oriented wurtzite-CdS based on the intensity and fullwidth half-maximum of the peak at $2 \theta$ equals $26.66^{\circ}$.

We see a similar trend from the UV-Vis spectra, also taken before the deposition of P3HT. Figure 4 shows the absorption spectra for the $\mathrm{ZnO}$ only, 1-dip, and 3-dip films before deposition of the P3HT layer. These spectra show that the 3-dip $\mathrm{CdS}$ attenuates the underlying $\mathrm{ZnO}$ peaks significantly more than the 1-dip films, indicating a thicker layer of $\mathrm{CdS}$ coating the $\mathrm{ZnO}$ nanowires.

Table 1 shows the solar cell results for the $\mathrm{ZnO}$ only, 1dip, and 3-dip devices. Values are reported for both "Day 1," which were measurements taken immediately after the devices were fabricated, and "Day 5", which were taken after 5 days of being stored in the air away from light in a drawer. Other groups have reported a significant increase in the efficiency of $\mathrm{ZnO}: \mathrm{P} 3 \mathrm{HT}$ solar cells after some exposure time to air, and we observe the same result; this effect has been attributed to either oxygen vacancies in the $\mathrm{ZnO}$ or the presence of oxygen in the air passivating surface conduction channels on the $\mathrm{ZnO}$ nanowires [15, 22, 23]. This improvement can be attributed primarily to an increase in the short-circuit current.

Results from the table show that the $500 \mathrm{~nm}$ devices produce the highest efficiency. This is in agreement with other reports that utilize a thickness of $\mathrm{ZnO}$ nanowire arrays between 150-500 nm [12-15]. For the larger thicknesses, we see a severe decrease in the open circuit voltage, leading to practically nonfunctional devices for the $2000 \mathrm{~nm}$ devices. This could be due to two possible causes: either the $\mathrm{ZnO}$ or $\mathrm{ZnO} / \mathrm{CdS}$ nanowires are shorting to the top silver electrode, and/or the low mobility of the P3HT layer degrades the performance as hole collection through the polymer has to occur at length scales of $1 \mu \mathrm{m}$ or greater. 


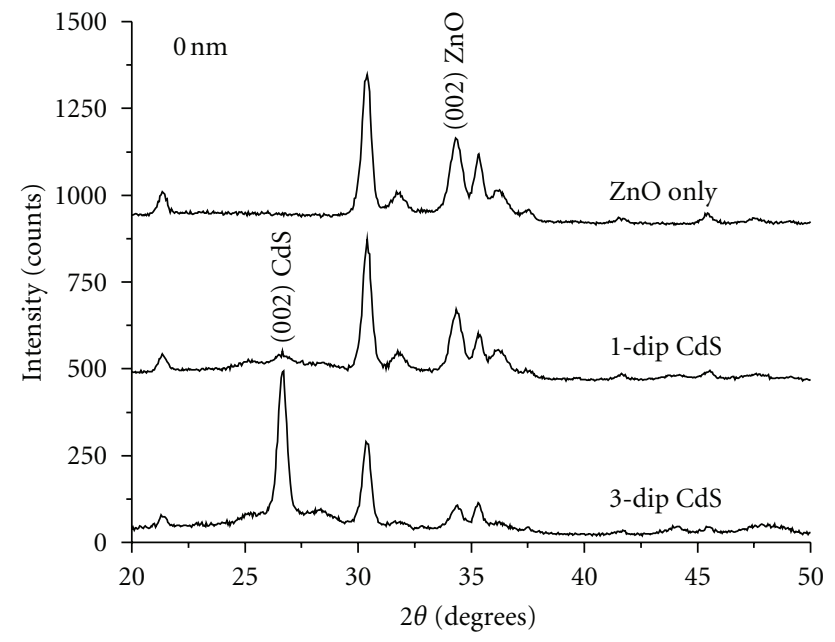

(a)

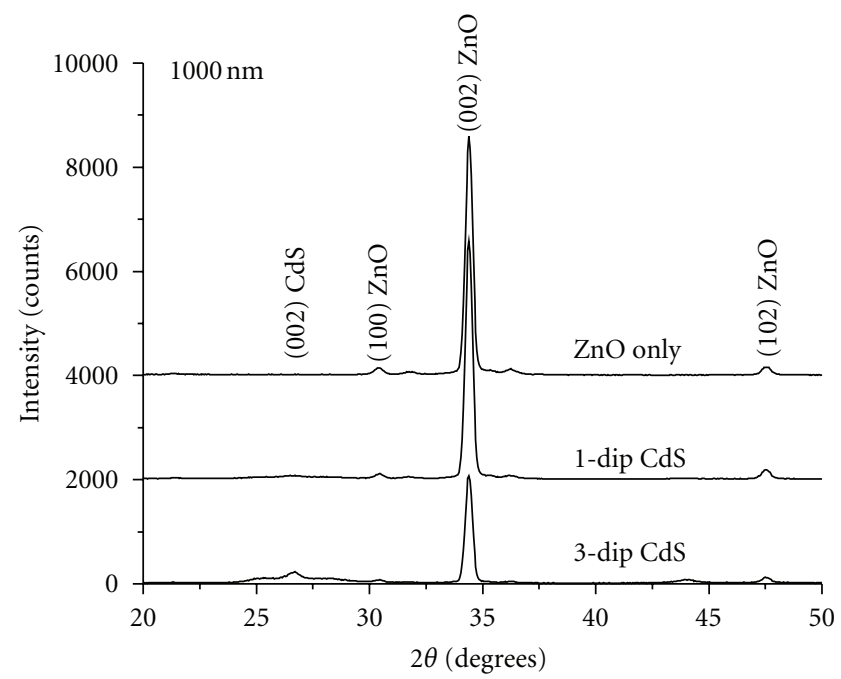

(c)

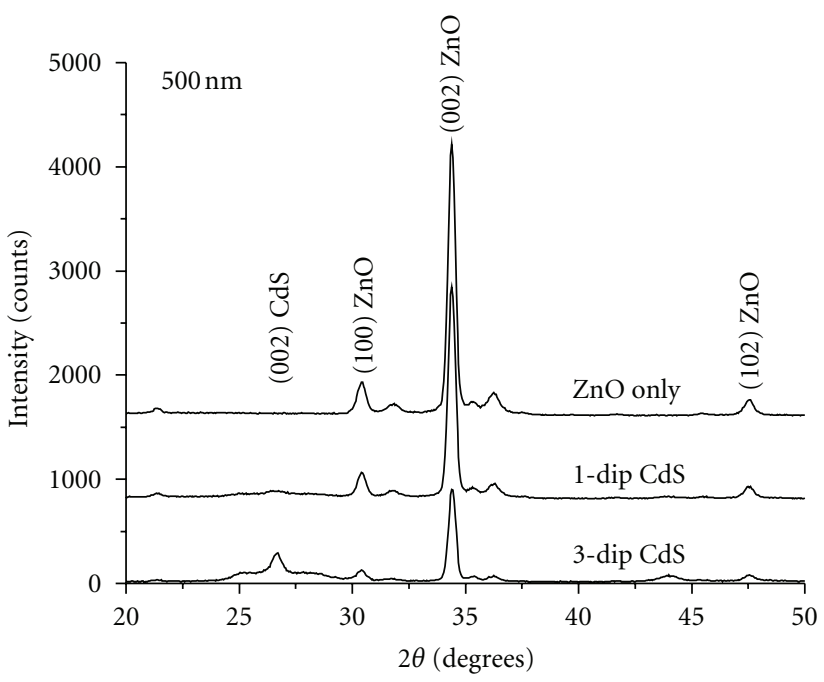

(b)

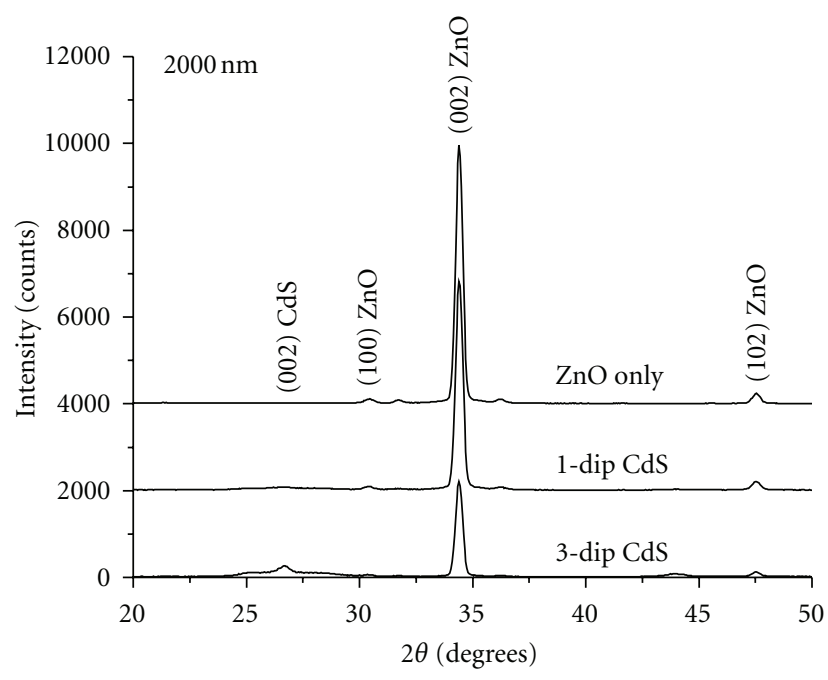

(d)

FIGURE 3: XRD spectra of films with no interlayer, 1-dip, and 3-dip CdS interlayers before P3HT deposition.

TABLe 1: Solar cell data for ZnO only, 1-dip CdS, and 3-dip CdS devices.

\begin{tabular}{cccccccccc}
\hline & \multirow{2}{*}{ Nanowire height $(\mathrm{nm})$} & \multicolumn{2}{c}{ Efficiency $(\%)$} & \multicolumn{2}{c}{ Voc $(\mathrm{V})$} & \multicolumn{3}{c}{ Jsc $\left(\mathrm{A} / \mathrm{cm}^{2}\right)$} & \multicolumn{2}{c}{ Fill factor $(\%)$} \\
& & Day 1 & Day 5 & Day 1 & Day 5 & Day 1 & Day 5 & Day 1 & Day 5 \\
\hline \multirow{3}{*}{ ZnO only } & 0 & 0.022 & 0.071 & 152 & 212 & $4.9 E-04$ & $1.0 E-03$ & 32.7 & 32.9 \\
& 500 & 0.015 & 0.282 & 381 & 394 & $8.9 E-05$ & $1.7 E-03$ & 43.2 & 40.9 \\
& 1000 & 0.009 & 0.131 & 147 & 146 & $1.7 E-04$ & $2.6 E-03$ & 36.2 & 33.9 \\
& 2000 & 0.000 & 0.007 & 10 & 24 & $7.5 E-05$ & $1.1 E-03$ & 43.9 & 20.9 \\
\hline \multirow{3}{*}{ 1-dip CdS } & 0 & 0.002 & 0.009 & 419 & 367 & $2.1 E-05$ & $1.4 E-04$ & 19.1 & 16.2 \\
& 500 & 0.015 & 0.112 & 421 & 399 & $1.0 E-04$ & $8.8 E-04$ & 33.8 & 31.8 \\
& 1000 & 0.002 & 0.000 & 17 & 10 & $6.4 E-04$ & $6.8 E-05$ & 15 & 78.6 \\
& 2000 & 0.000 & 0.002 & 10 & 10 & $5.1 E-05$ & $2.9 E-04$ & 19.1 & 75.3 \\
\hline 3-dip CdS & 0 & 0.008 & 0.017 & 207 & 313 & $2.9 E-04$ & $2.1 E-04$ & 24.5 & 31.7 \\
& 500 & 0.282 & 0.442 & 364 & 428 & $2.1 E-03$ & $2.9 E-03$ & 37.1 & 35.7 \\
& 1000 & 0.023 & 0.013 & 66 & 44 & $1.4 E-03$ & $1.2 E-03$ & 23.3 & 19.1 \\
& 2000 & 0.001 & 0.004 & 10 & 10 & $7.1 E-04$ & $9.5 E-04$ & 21.8 & 94.1 \\
\hline
\end{tabular}




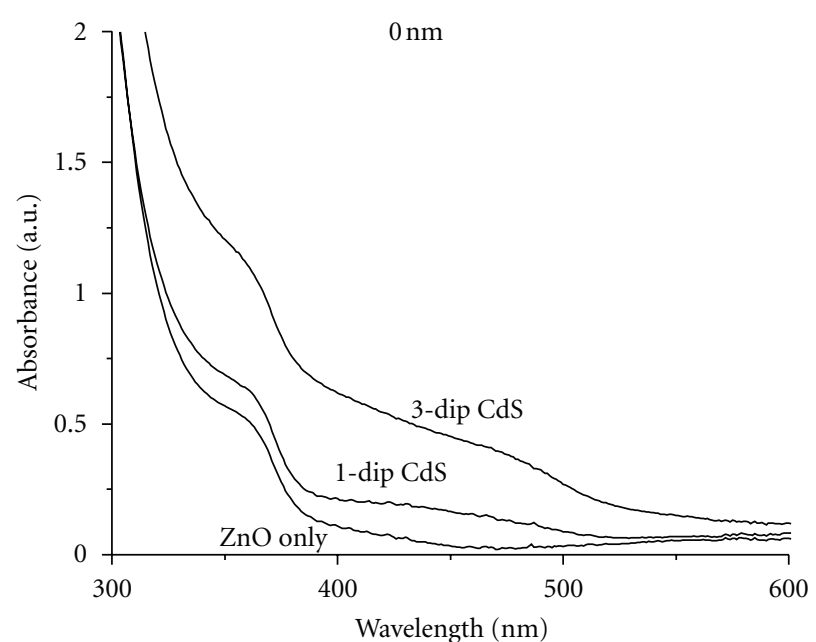

(a)

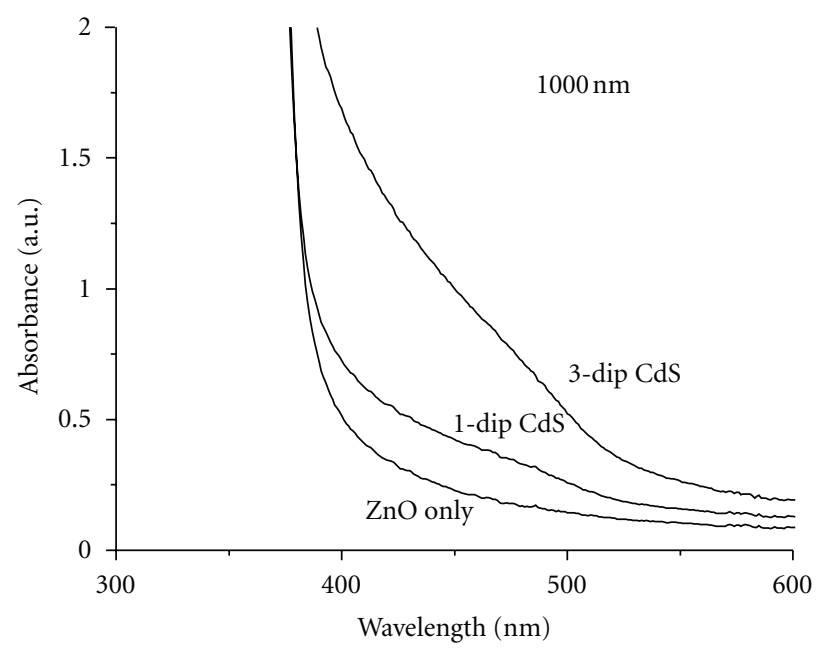

(c)

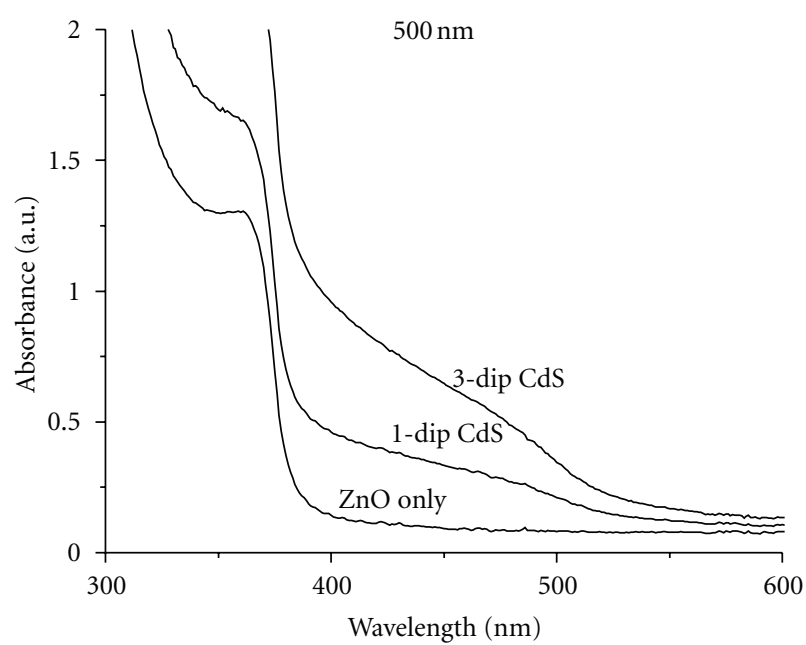

(b)

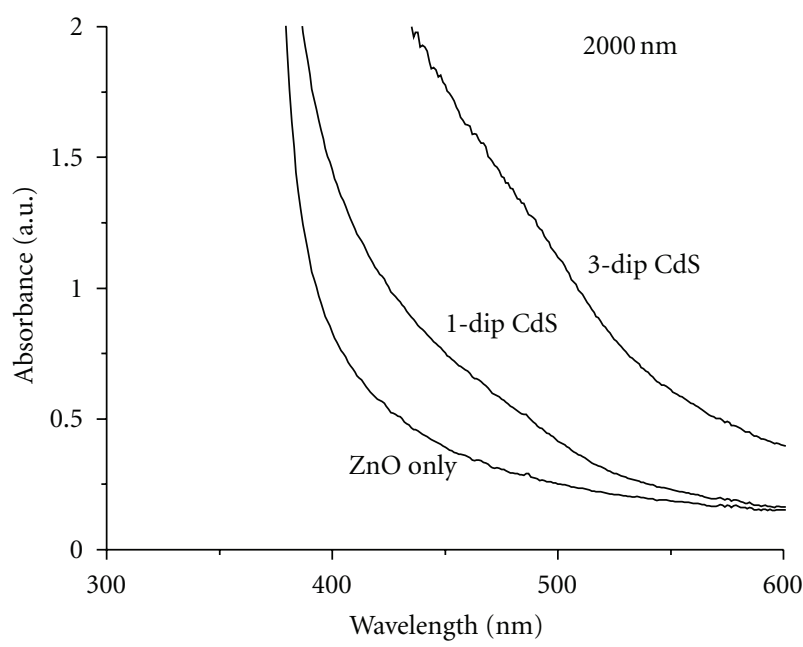

(d)

FIgURE 4: UV-Vis spectra of films with no interlayer, 1-dip, and 3-dip CdS interlayers before P3HT deposition.

The maximum efficiency for all of the devices in Table 1 is achieved with the $500 \mathrm{~nm} 3$-dip CdS devices. We believe that the 3-dip CdS produces a higher quality CdS as compared to the EZ CdS due to the higher deposition temperature and slower growth rate. The 1-dip CdS devices perform significantly worse than even the uncoated $\mathrm{ZnO}$ devices; this may be due to incomplete coverage of the zinc oxide nanowire, producing interfacial defects leading to recombination.

Figure 5 shows the EZ CdS layer deposited on a $2000 \mathrm{~nm}$ $\mathrm{ZnO}$ layer. Even though the time of this deposition was the same as the 1-dip recipe, 25 minutes, the thickness appears to be similar to or even slightly thicker than the 3-dip films. This is in agreement with our expectations, since the EZ CdS recipe is simply $\mathrm{Cd}\left(\mathrm{NO}_{3}\right)_{2}$ and thioacetamide with no complexing agents or stabilizers to control the reaction rate. The 1-dip and 3-dip recipes, although they are done at a higher temperature, utilize sodium citrate as a complexing agent to slow the reaction rate by controlling the amount of free cadmium. One difference between the 3-dip and EZ CdS recipes is that the EZ CdS appears to produce a more uniform coating along the length of the nanowires, whereas the 3-dip recipe produces that thickness at the top of the nanowires, but appears to become more thin towards the bottom of the nanowires, close to the substrate.

Although the SEM micrographs seem to show a fairly similar thickness between the EZ CdS films and the 3dip films, the XRD spectra for the EZ CdS films show a much greater degree of attenuation of the peaks from the underlying $\mathrm{ZnO}$ nanowires. Figure 6 shows the spectra for all of the different thicknesses for the EZ CdS films prior to P3HT deposition. For the EZ CdS films with a nanowire thickness of 500 and $1000 \mathrm{~nm}$, the (002) CdS peak is actually more intense than the (002) peak for $\mathrm{ZnO}$, and even for the $2000 \mathrm{~nm}$ the two peaks are of similar intensity. However, Figure 3 shows that for the $500-2000 \mathrm{~nm}$ devices the (002) $\mathrm{ZnO}$ peak is always larger 3-dip CdS films, from 3 to $10 \mathrm{x}$ 

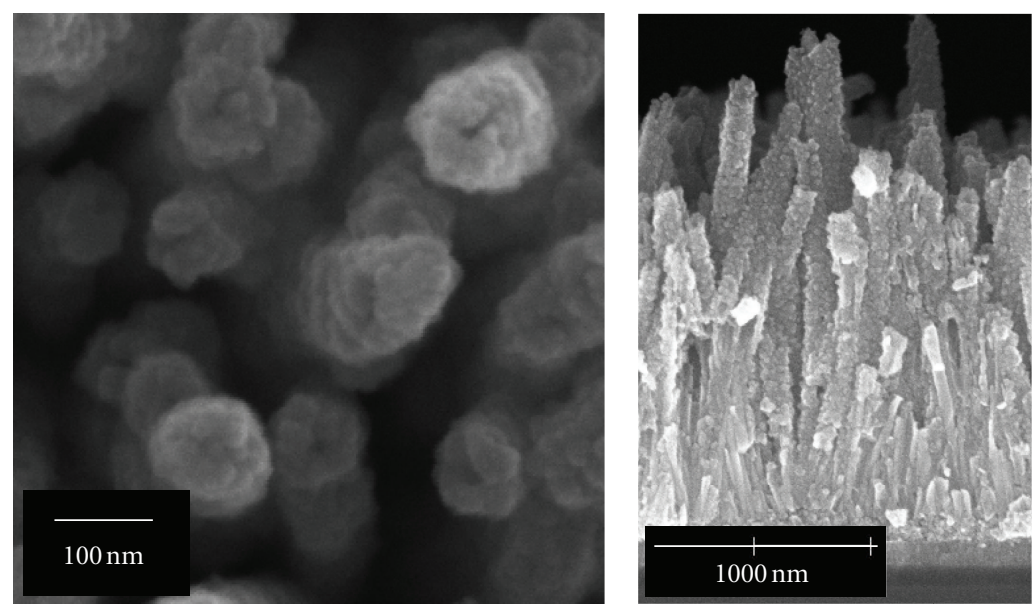

Figure 5: SEM images of the EZ CdS interlayer on $2000 \mathrm{~nm}$ ZnO nanowires; left lateral view, right cross-section view.

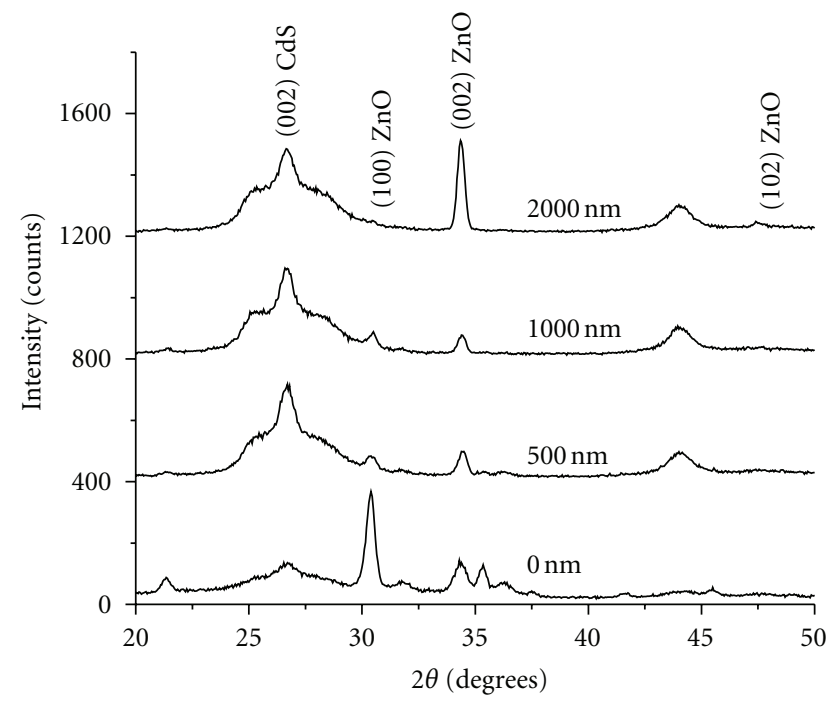

FIGURE 6: XRD spectra of the EZ CdS films.

more intense. We attribute this greater attenutation to a more uniform coating of the nanowires from top to bottom and possibly a slightly thicker layer of $\mathrm{CdS}$ on the nanowires.

The solar cell characteristics of the EZ CdS devices are summarized in Table 2. Here the maximum efficiency is achieved with the $1000 \mathrm{~nm}$ devices; we attribute this to a thicker coating along the entire length of the nanowire, which may be completely filling in the nanowire array at the bottom near the substrate, effectively shortening the height of the nanowires. The fact that the $2000 \mathrm{~nm}$ devices actually work and have an efficiency of $0.157 \%$ seems to support this hypothesis that the nanowire array is being filled in to some extent. Another interesting note about the EZ CdS devices is that they show a much greater increase in efficiency between the "Day 1" and "Day 5" measurements compared to the 3dip CdS devices: an almost 10x increase for the $1000 \mathrm{~nm} \mathrm{EZ}$ $\mathrm{CdS}$ devices compared to less than a doubling for the $500 \mathrm{~nm}$ 3-dip devices.

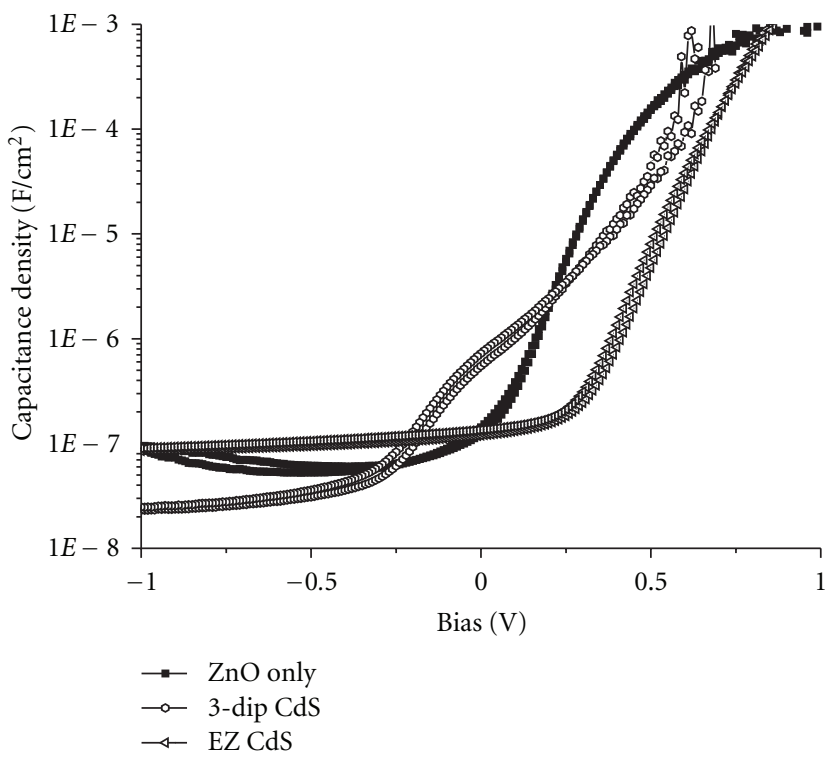

Figure 7: Low-frequency CV sweeps of ZnO only, 3-dip CdS, and EZ CdS devices on $500 \mathrm{~nm}$ nanowire arrays.

Another possibility for the higher performance of the 3-dip CdS compared to the EZ CdS devices with $500 \mathrm{~nm}$ nanowires is that the 3-dip deposition method produces a higher quality semiconductor layer, due to slower deposition rate at higher temperature. The XRD spectra for the films with no nanowires show that the 3 -dip recipe produces a more intense (002) wurtzite-CdS peak relative to the other CdS peaks, indicating larger crystallites of (002) oriented CdS in the 3-dip films compared to the EZ CdS films. In order to investigate this possibility, we carried out low frequency $(100 \mathrm{~Hz})$ capacitance measurements on representative devices with a $500 \mathrm{~nm}$ nanowire array. The results are shown in Figure 7.

At $-1 \mathrm{~V}$, the $\mathrm{ZnO}$ only and the EZ CdS devices have a similar capacitance density, with the $\mathrm{ZnO}$ only actually having a lower capacitance between 0 and $-0.75 \mathrm{~V}$. However, 
TABLE 2: Solar cell data for EZ CdS devices.

\begin{tabular}{cccccccccc}
\hline & \multirow{2}{*}{ Nanowire height $(\mathrm{nm})$} & \multicolumn{2}{c}{ Efficiency $(\%)$} & \multicolumn{2}{c}{ Voc $(\mathrm{V})$} & \multicolumn{3}{c}{ Jsc $\left(\mathrm{A} / \mathrm{cm}^{2}\right)$} & \multicolumn{3}{c}{ Fill factor $(\%)$} \\
& & Day 1 & Day 5 & Day 1 & Day 5 & Day 1 & Day 5 & Day 1 & Day 5 \\
\hline \multirow{3}{*}{ EZ CdS } & 0.004 & 0.032 & 535 & 535 & $2.2 E-05$ & $2.1 E-04$ & 29.9 & 29.2 \\
& 500 & 0.012 & 0.183 & 508 & 545 & $6.8 E-05$ & $9.8 E-04$ & 34.5 & 34.6 \\
& 1000 & 0.043 & 0.372 & 344 & 263 & $3.8 E-04$ & $3.7 E-03$ & 32.9 & 32.7 \\
& 2000 & 0.026 & 0.157 & 273 & 162 & $3.3 E-04$ & $3.4 E-03$ & 29.1 & 28.7 \\
\hline
\end{tabular}

the capacitance density for the 3 -dip CdS film at $-1 \mathrm{~V}$ is approximately an order of magnitude lower than the other two devices measured. This suggests a greater depletion width in the 3-dip device, indicating a higher quality, more resistive semiconductor layer at the heterojunction.

\section{Conclusions}

We have shown that the conformal coverage of $\mathrm{ZnO}$ nanowires is critical to achieving improved performance using CdS interlayers. For the thin CdS layers that do not appear to fully coat the $\mathrm{ZnO}$ nanowires, the solar cell performance is actually worse than for $\mathrm{ZnO}$ alone. We have also demonstrated that a similar performance can be achieved using CdS deposited by two different CBD recipes; although this performance is achieved for two different nanowire array thicknesses, we believe this is due to the density of CdS growth at the bottom of the nanowire array.

\section{References}

[1] J. Zhou, N. Xu, and Z. L. Wang, "Dissolving behavior and stability of $\mathrm{ZnO}$ wires in biofluids: a study on biodegradability and biocompatibility of $\mathrm{ZnO}$ nanostructures," Advanced Materials, vol. 18, no. 18, pp. 2432-2435, 2006.

[2] M. Ohyama, H. Kozuka, and T. Yoko, "Sol-gel preparation of $\mathrm{ZnO}$ films with extremely preferred orientation along (002) plane from zinc acetate solution," Thin Solid Films, vol. 306, no. 1, pp. 78-85, 1997.

[3] L. E. Greene, M. Law, J. Goldberger et al., "Low-temperature wafer-scale production of $\mathrm{ZnO}$ nanowire arrays," Angewandte Chemie-International Edition, vol. 42, no. 26, pp. 3031-3034, 2003.

[4] M. Law, L. E. Greene, J. C. Johnson, R. Saykally, and P. Yang, "Nanowire dye-sensitized solar cells," Nature Materials, vol. 4, no. 6, pp. 455-459, 2005.

[5] O. L. Muskens, J. G. Rivas, R. E. Algra, E. P. A. M. Bakkers, and A. Lagendijk, "Design of light scattering in nanowire materials for photovoltaic applications," Nano Letters, vol. 8, no. 9, pp. 2638-2642, 2008.

[6] H. Lu and C. Gang, "Analysis of optical absorption in silicon nanowire arrays for photovoltaic applications," Nano Letters, vol. 7, no. 11, pp. 3249-3252, 2007.

[7] S. H. Ko, D. Lee, H. W. Kang et al., "Nanoforest of hydrothermally grown hierarchical $\mathrm{ZnO}$ nanowires for a high efficiency dye-sensitized solar cell," Nano Letters, vol. 11, no. 2, pp. 666671,2011

[8] S. P. Chang, C. Y. Lu, S. J. Chang et al., "A novel fabrication of $\mathrm{p}$-n diode based on $\mathrm{ZnO}$ nanowire/p-NiO heterojunction," Japanese Journal of Applied Physics, vol. 50, no. 1, Article ID 01AJ05, 2011.
[9] B. D. Yuhas and P. Yang, "Nanowire-based all-oxide solar cells," Journal of the American Chemical Society, vol. 131, no. 10, pp. 3756-3761, 2009.

[10] C. Cheng, T. L. Wang, L. Feng et al., "Vertically aligned $\mathrm{ZnO} /$ amorphous-Si core-shell heterostructured nanowire arrays," Nanotechnology, vol. 21, no. 47, Article ID 475703, 2010.

[11] H. H. Li, P. Y. Yang, S. M. Chiou, H. W. Liu, and H. C. Cheng, "A novel coaxial-structured amorphous-silicon p-i-n solar cell with Al-doped $\mathrm{ZnO}$ nanowires," IEEE Electron Device Letters, vol. 32, no. 7, pp. 928-930, 2011.

[12] D. C. Olson, Y. J. Lee, M. S. White et al., "Effect of polymer processing on the performance of poly(3-hexylthiophene)/ZnO nanorod photovoltaic devices," Journal of Physical Chemistry C, vol. 111, no. 44, pp. 16640-16645, 2007.

[13] H. E. Unalan, P. Hiralal, D. Kuo, B. Parekh, G. Amaratunga, and M. Chhowalla, "Flexible organic photovoltaics from zinc oxide nanowires grown on transparent and conducting single walled carbon nanotube thin films," Journal of Materials Chemistry, vol. 18, no. 48, pp. 5909-5912, 2008.

[14] Y. Y. Lin, Y. Y. Lee, L. Chang, J. J. Wu, and C. W. Chen, "The influence of interface modifier on the performance of nanostructured $\mathrm{ZnO} /$ polymer hybrid solar cells," Applied Physics Letters, vol. 94, no. 6, Article ID 063308, 2009.

[15] L. E. Greene, M. Law, B. D. Yuhas, and P. Yang, " $\mathrm{ZnO}-\mathrm{TiO}_{2}$ core-shell nanorod/ $\mathrm{P}_{3} \mathrm{HT}$ solar cells," Journal of Physical Chemistry C, vol. 111, no. 50, pp. 18451-18456, 2007.

[16] P. Atienzar, T. Ishwara, B. N. Illy et al., "Control of photocurrent generation in polymer/ZnO nanorod solar cells by using a solution-processed $\mathrm{TiO}_{2}$ overlayer," Journal of Physical Chemistry Letters, vol. 1, no. 4, pp. 708-713, 2010.

[17] E. D. Spoerke, M. T. Lloyd, E. M. McCready, D. C. Olson, Y. J. Lee, and J. W. P. Hsu, "Improved performance of poly(3hexylthiophene)/zinc oxide hybrid photovoltaics modified with interfacial nanocrystalline cadmium sulfide," Applied Physics Letters, vol. 95, no. 21, Article ID 213506, 2009.

[18] L. E. Greene, M. Law, D. H. Tan et al., "General route to vertical $\mathrm{ZnO}$ nanowire arrays using textured $\mathrm{ZnO}$ seeds," Nano Letters, vol. 5, no. 7, pp. 1231-1236, 2005.

[19] M. Sotelo-Lerma, M. A. Quevedo-López, R. A. Orozco-Terán, R. Ramírez-Bon, and F. J. Espinoza-Beltrán, "Characterization of CdS-NaX composite material synthesized in alkaline solution," Journal of Physics and Chemistry of Solids, vol. 59, no. 2, pp. 145-149, 1998.

[20] A. L. Salas-Villasenor, I. Mejia, J. Hovarth et al., "Impact of gate dielectric in carrier mobility in low temperature chalcogenide thin film transistors for flexible electronics," Electrochemical and Solid-State Letters, vol. 13, no. 9, pp. H313-H316, 2010.

[21] E. D. Spoerke, M. T. Lloyd, Y. J. Lee et al., "Nanocrystal layer deposition: surface-mediated templating of cadmium sulfide 
nanocrystals on zinc oxide architectures," Journal of Physical Chemistry C, vol. 113, no. 37, pp. 16329-16336, 2009.

[22] W. J. E. Beek, M. M. Wienk, and R. A. J. Janssen, "Hybrid solar cells from regioregular polythiophene and $\mathrm{ZnO}$ nanoparticles," Advanced Functional Materials, vol. 16, no. 8, pp. 11121116, 2006.

[23] D. C. Olson, S. E. Shaheen, R. T. Collins, and D. S. Ginley, "The effect of atmosphere and $\mathrm{ZnO}$ morphology on the performance of hybrid poly(3-hexylthiophene)/ZnO nanofiber photovoltaic devices," Journal of Physical Chemistry C, vol. 111, no. 44, pp. 16670-16678, 2007. 

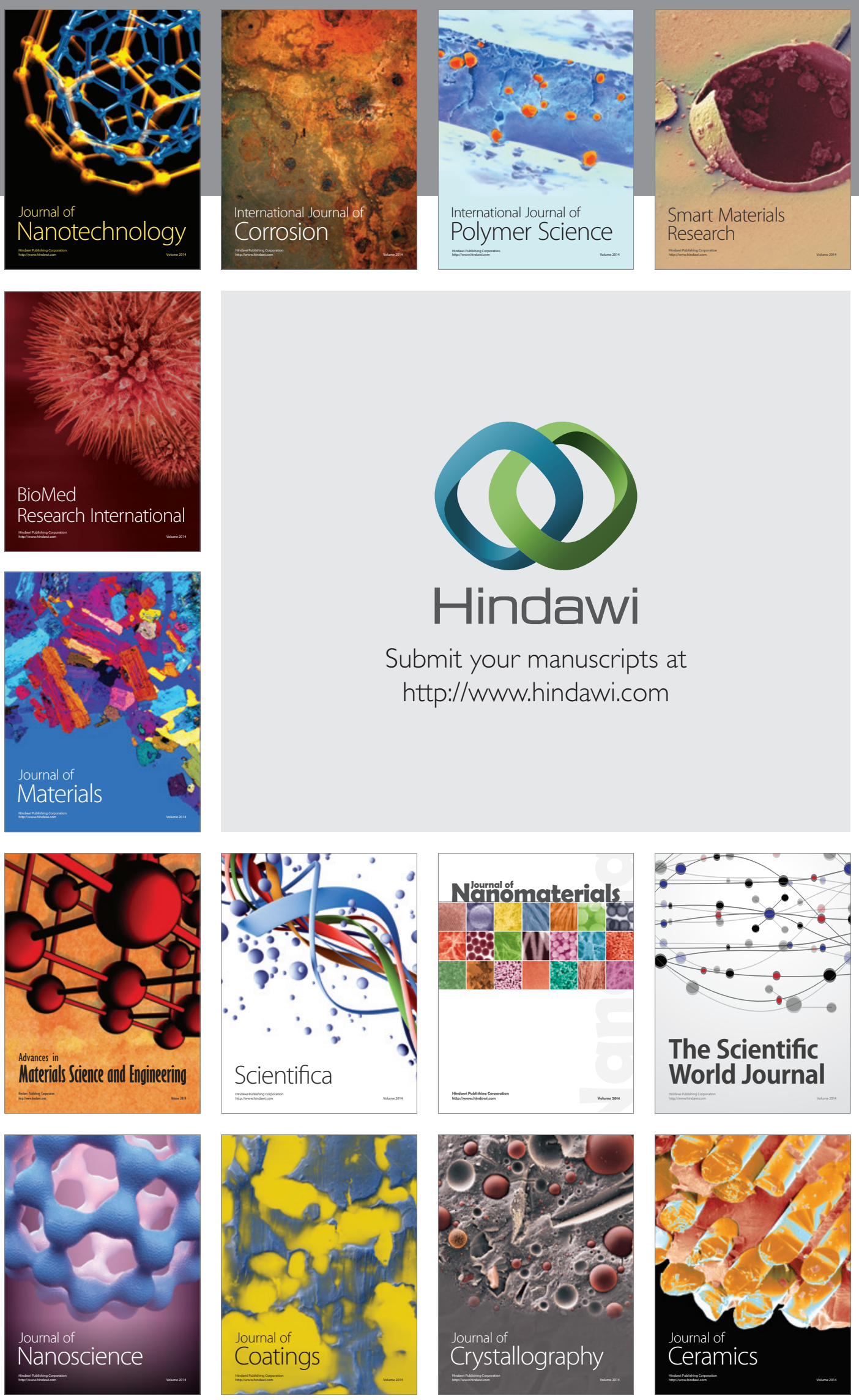

The Scientific World Journal

Submit your manuscripts at

http://www.hindawi.com

\section{World Journal}

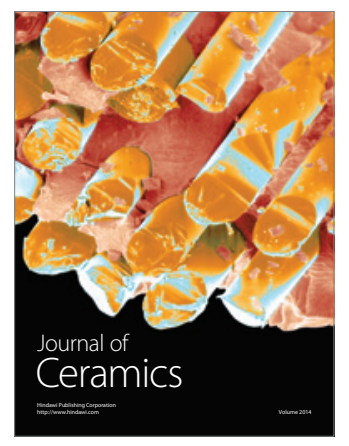

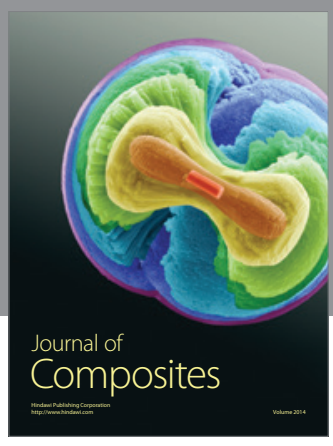
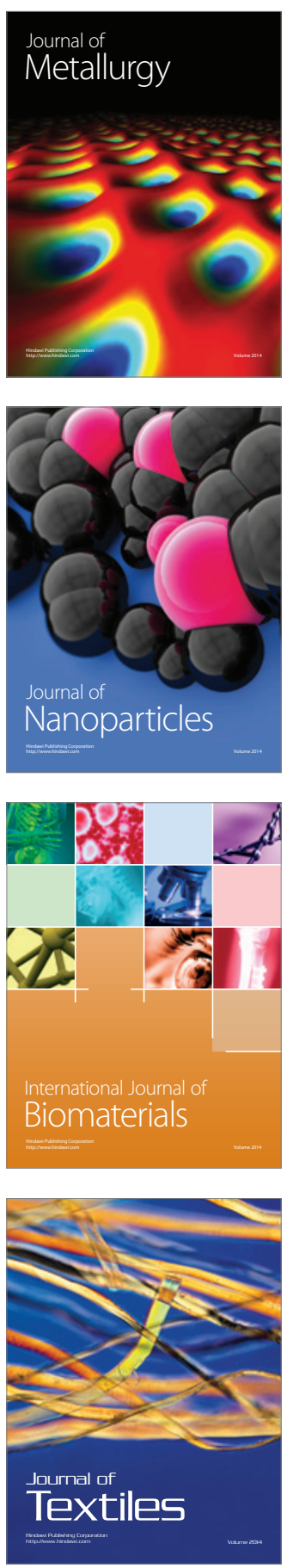